\title{
Urgența în dreptul internațional. Justificarea urgenței în baza unor clauze în tratate
}

\author{
Conf. univ. dr. Ion Gâlea
}

Facultatea de Drept, Universitatea din București

Rezumat: Studiul propune examinarea - în lumina provocărilor generate de pandemia COVID-19 - a întrebării dacă și cum Statele ar putea suspenda exacutarea unor obligații de drept internațional într-o situație de urgență. Studiul se concentrează pe tipologia clauzelor din tratate, care ar permite anumite excepții (cauzele care înlătură caracterul ilicit al faptei urmând a fi examinate într-un studiu ulterior). Pe de o parte, cercetarea examinează excepțiile prevăzute de GATT în articolele XX (excepții generale) și XXI (excepții privind securitatea) și, pe de altă parte, tipologia clauzelor în Tratatele Bilaterale de Investiții. De asemenea, este examinată practica relevantă a grupurilor speciale și organelor de apel OMC, precum și a tribunalelor arbitrale în materia investițiilor.

Cuvinte cheie: justificarea urgenței; clauze în tratate; excepții; Organizația Mondială a Comerțului; Tratate Bilaterale de Investiții

\section{Urgency in International Law. Justifiying Urgency on the Basis of Treaty Clauses}

\begin{abstract}
The study proposes to examine - in the light of the challenges raised by the COVID-19 pandemic - whether and how States can suspend the performance of international law obligations in a situation of emergency. The study focuses on patterns of treaty clauses that may allow for certain exceptions (while the circumstances precluding wrongfulness are subject to a subsequent study). On one side, the research examines the GATT exceptions provided in articles XX (general exceptions) and XXI (security exceptions), and on the other side, the patterns of clauses within Bilateral Investment Treaties. Relevant case-law of WTO panels, appelate bodies and of investment arbitration tribunals is also examined.
\end{abstract}

Key-words: justification of urgency; treaty clauses; exceptions; World Trade Organization; Bilateral Investment Treaties

\section{Introducere}

Acest studiu, destinat Forumului online al Analelor Universităţii din București, urmărește prezentarea într-o manieră succintă "primei părți" a ideilor expuse în cadrul Conferinței "Urgența în drept", organizată de Facultatea de Drept a Universității din București în perioada 30-31 martie 2020. Întrebarea la care se caută răspuns este următoarea: într-o situație ,de urgență” - cum este pandemia COVID-19 - cum pot justifica statele suspendarea unor obligații de drept internațional sau adoptarea unor măsuri pentru 
combaterea epidemiei, care, în lipsa unei ,justificări”, nu ar fi conforme unor obligații internaționale în vigoare pentru statul respectiv?

De exemplu, suspendarea de către un stat a exporturilor medicamentelor sau produselor sanitare poate fi justificată în raport cu obligațiile rezultate din tratele comerciale la care acel stat este parte? Sau adoptarea de către un stat a unor măsuri de interzicere a desfășurării unor activități ar putea fi privită de către investitori din state terțe ca pe o "expropriere indirectă”, sau o măsură care încalcă „tratamentul just și echitabil”, în sensul prevederilor relevante din tratatele pentru promovarea și protejarea reciprocă a investițiilor? ${ }^{1}$

Prezentul studiu succint propune să examineze justificarea în temeiul unor clauze în tratatele economice sau comerciale. Această secțiune reprezintă prima parte dintr-un studiu mai amplu a justificării urgenței, partea a doua fiind bazată pe analizarea clauzelor care înlătură caracterul ilicit al faptei, în conformitate cu dreptul internaţional al răspunderii statelor: forța majoră, starea de primejdie și starea de necesitate ${ }^{2}$. Totuşi, înainte de a justifica o acțiune sau inacțiune prin dreptul internațional general - respectiv clauzele care înlătură răspunderea internaţională - statele vor încerca să justifice suspendarea executării obligaţiilor dintr-un tratat, chiar în temeiul prevederilor acelui tratat. De cele mai multe ori, tratatele mai ales cele privind comerțul și investițiile - nu sunt "blocuri inflexibile", ci conțin clauze a căror interpretare poate oferi statelor justificarea adoptării diferitelor măsuri.

Propunem examinarea, într-o primă parte, a clauzelor care ,au servit drept inspirație” în redactarea majorităţii tratatelor comerciale sau de investiții, respectiv excepțiile generale din Acordul General privind Tarifele și Comerțul (GATT), urmând ca în partea a doua să fie examinate clauzele ,tip” ale tratatelor privind promovarea și protejarea reciprocă a investiţiilor.

\section{Acordul General privind Tarifele și Comerțul GATT ${ }^{3}$}

\section{I.1. Excepțiile generale}

Acordul General privind Tarifele și Comerțul (GATT) conține excepțiile generale prevăzute în articolul XX, care au reprezentat o bază, o sursă de inspirație pentru acorduri

\footnotetext{
${ }^{1}$ Oliver Hailes, Epidemic Sovereignty? Contesting investment treaty claims arising from coronavirus measures, EJIL: Talk!, Blog of the European Journal of International Law, 27 March 2020, https://www.ejiltalk.org/epidemic-sovereignty-contesting-investment-treaty-claims-arising-from-coronavirusmeasures/ (accesat 12 aprilie 2020); cu privire la tratamentul just și echitabil - A. Newcombe, L. Paradell, Law and Practice of Investment Treaties. Standards of Treatment, Wolters Kluwer, 2009, p. 264.

${ }^{2}$ International Law Commission, Articles on the Responsibility of States for International Wrongful Acts (with commentaries), 2001, Yearbook of the International Law Commission, 2001, vol. II, p. 31-143, art. 23, 24, 25; cu privire la aplicarea acestor articole la COVID-19, a se vedea: Federica Paddeu, Frey Jephcott, COVID-19 and Defences in the Law of State Responsibility: Part I/Part II, EJIL: Talk!, Blog of the European Journal of International Law, 17 March 2020, https://www.ejiltalk.org/covid-19-and-defences-in-the-law-of-stateresponsibility-part-i/, https://www.ejiltalk.org/covid-19-and-defences-in-the-law-of-state-responsibility-part-ii/ (accesat 12 aprilie 2020).

${ }^{3}$ În forma sa inițială, aplicat provizoriu începând cu 1950 - United Nations Treaty Series, vol. 64 (1950), p. 187; GATT 1994 este anexat Acordului de la Marrakesh privind înființarea Organizației Mondiale a Comerțului, Anexa 1A, United Nations Treaty Series, vo. 1867 (1995), p. 187.
} 
viitoare, atât în materie de comerț, cât și în materie de investiții ${ }^{4}$. Excepțiile generale acoperă o paletă amplă de domenii, însă textul relevant pentru domeniul sănătății publice este următorul:

"Sub rezerva ca asemenea măsuri să nu fie aplicate intr-un mod care să constituie un mijloc de discriminare arbitrară sau nejustificată între ţările în care există aceleaşi condiţii, sau o restricţie deghizată a comertului internaţional, nimic în acest Acord nu va fi interpretat ca împiedicând adoptarea sau aplicarea de către o parte contractantă a măsurilor: [...]

b) necesare pentru a proteja viaţa sau sănătatea oamenilor, a animalelor sau a plantelor; [...]”."

Chiar dacă GATT acoperă comerțul cu bunuri, trebuie precizat că Acordul General privind Comerțul cu Servicii conține o excepție identică în ceea ce privește sănătatea publică, la articolul XIV litera b).

Practica sistemului OMC de soluționare a diferendelor (cazurile Statele Unite Standarde pentru benzina reformulată și convențională și Statele Unite - Creveți) demonstrează că pentru analizarea conformității unei măsuri cu articolul XX, se evaluează, în primul rând, încadrarea măsurii, cu titlu provizoriu, în criteriile enunțate la literele a) - j) şi, în al doilea rând, conformitatea cu paragraful introductiv al articolului (așa-numitul "chapeau") 5 .

În ceea ce privește prima condiție [în cazul măsurilor pentru combaterea unei pandemii - încadrarea în litera b] este necesară verificarea "scopului măsurii" și a "necesității". Circumscrierea măsurilor legate de COVID-19 în "scopul" enunţat de articolul XX b) nu prezintă nicio dificultate, având în vedere practica sistemului OMC de soluționare a diferendelor (de exemplu, în cazul Thailanda - Țigarete, Grupul special ("Panelul") a considerat că măsurile pentru combaterea fumatului se încadrează în articolul XX b) din GATT) ${ }^{6}$. "Necesitatea" presupune însă evaluarea alternativelor la măsura în cauză: în același caz Thailanda - Țigarete, Panelul a considerat că interzicerea importului de țigări nu satisfăcea criteriul „necesităţii”, existând alternative precum etichetarea produselor și expunerea ingredientelor ${ }^{7}$. Totuși, în cazul $C E-A z b e s t$, organul de apel a reținut (în raport cu riscul major pe care îl antrenau produsele din azbest): "cu cât mai vital sau important este interesul sau valorile comune", cu atât mai ușoară este dovedirea caracterului necesar al unei măsuri ${ }^{8}$. Importanța apărării sănătății populației în raport cu pandemia COVID-19 nu poate fi negată, însă necesitatea fiecărei măsuri ar presupune, cu siguranță, o analiză de la caz la caz.

\footnotetext{
${ }^{4}$ De exemplu, articolul 36 din Tratatul privind funcționarea Uniunii Europene (fostul articol 30 din Tratatul privind Comunitatea Europeană) are ca sursă de inspirație articolul XX din GATT.

${ }^{5}$ Appellate Body Report, United States - Standards for Reformulated and Conventional Gasoline, WT/DS2/AB/R, adopted 20 May 1996, para. 22; Appellate Body Report, United States — Import Prohibition of Certain Shrimp and Shrimp Products, WT/DS58/AB/R, adopted 6 November 1998, para. 119120; Peter Van den Bossche, The Law and Policy of the World Trade Organization, Cambridge University Press, 2005, p. 601-602.

${ }^{6}$ Thailand - Restrictions on Importation of and Internal Taxes on Cigarettes, Report of the Panel adopted on 7 November 1990 (DS10/R - 37S/200), para. 73.

${ }^{7}$ Ibid., para. 73-77; Peter Van den Bossche, op. cit., p. 605.

${ }^{8}$ Appellate Body Report, European Communities - Measures Affecting Asbestos and Asbestos-Containing Products, WT/DS135/AB/R, adopted 5 April 2001, para. 172; cu privire la necesitate, a se vedea și Korea Various measures on Beef, Appelate Body Report, WT/DS161/AB/R, WT/DS169/AB/R, 11 December 2000, para. 146.
} 
În ceea ce privește analizarea condițiilor din paragraful introductiv al articolului XX ("chapeau"), scopul principal al analizei este evitarea abuzului, asigurarea unui echilibru între valoarea urmărită și interesele celorlalte state. Pentru analizarea acestui echilibru, trebuie avute în vedere nu „concepția, arhitectura și structura” măsurii, ci și modul în care, în mod practic, măsura este aplicată: standardele din „chapeau” se aplică atât elementelor de substanță, cât și celor procedurale privind aplicarea măsurii ${ }^{9}$. Și în aceste situații, analizarea „echilibrului” trebuie realizată de la caz la caz.

\section{I.2. Excepțiile privind securitatea}

Un argument „subsecvent” articolului XX b) este reprezentat de excepțiile privind securitatea conținute de GATT. Posibilitatea invocării excepției privind securitatea apare ca fiind plauzibilă, având în vedere anvergura și gravitatea pandemiei COVID-19. Textul relevant din GATT este conținut în articolul XXI, ale cărui prevederi relevante dispun:

"Nicio prevedere a prezentului Acord nu va fi interpretată:

[...] b) ca împiedicând o parte contractantă de a lua toate măsurile pe care le va considera necesare pentru apărarea intereselor esenţiale ale securităţii sale:

(iii) aplicate în timp de război sau în cazul unei grave încordări internaţionale; [...]. “

Prevederea a fost privită, în doctrină, ca oferind posibilitatea largă de a proteja orice interes legitim de securitate, inclusiv interese esențiale de politică externă (de asemenea, termenul "grave încordări internaționale" a fost privit în mod extensiv) ${ }^{10}$. Cazurile în care, însă, prevederea a fost invocată în mod formal sunt însă rare. Totuși, un exemplu este reprezentat de raportul Grupului special (Panel) în cazul Rusia - Măsuri privind traficul în tranzit (2019) ${ }^{11}$, în care Rusia a invocat în mod explicit articolul XXI b) iii), pentru a justifica suspendarea traficului între Ucraina și - spre exemplu - Kazahstan, începând cu 2016, pe fondul tensiunilor din Donbass și Luhansk. Grupul special (Panelul) a explicat înțelesul termenului "interes esențial de securitate" ca reprezentând "acele interese care se referă la funcțiile care țin de chintesența statului, și anume protecția teritoriului și a populației de amenințări externe, apărarea ordinii de drept și a ordinii publice în plan intern" 12 . Recurgând la interpretarea literală, Panelul a explicat sintagma "gravă încordare internațională" (chiar dacă traducerea în limba română a GATT este publicată în Monitorul Oficial, limba română nu este "de referință" pentru interpretarea textului - notăm că în limba engleză, formula echivalentă este "emergency in international relations") ca semificând "o

\footnotetext{
${ }^{9}$ Appellate Body Report, United States — Import Prohibition of Certain Shrimp and Shrimp Products, WT/DS58/AB/R, adopted 6 November 1998, para. 160; Lorand Bartels, The Chapeau of the General Exceptions in the WTO GATT and GATS Agreements: A Reconstruction, American Journal of International Law, vol. 109 (2015), p. 95-125, 99.

${ }^{10}$ Hannes L. Schloemann, Stefan Ohlhoff, "Constitutionalization" and Dispute Settlement in the WTO: National Security as an Issue of Competence, American Journal of International Law, vol. 93 (1999), p. 424444.
}

\footnotetext{
${ }^{11}$ Panel Report, Russia - Measures concerning Traffic in Transit, WT/DS512/R, 5 April 2019.

${ }^{12}$ Ibid., para. 7.130.
} 
situație, un pericol sau un conflict, care apare neașteptat și care presupune acțiune urgentă”, precum și o "nevoie presantă" legată de "o stare, pericol sau un dezastru într-o regiune"13.

Un element important este reprezentat de faptul că Panelul a arătat că formula "pe care le va considera necesare" în textul articolului XXI b) nu permite determinarea subiectivă din partea statului care invocă acea clauză (textul nu este ,self-judging”), ci presupune o „determinare obiectivă a cerințelor enumerate în subparagrafele i) - iii)"14. Pe fond, Panelul a acceptat însă argumentul invocat de Rusia, bazat pe articolul XXI b) iii) ${ }^{15}$.

\section{Clauze în tratatele privind promovarea și protejarea reciprocă a investițiilor}

\section{II.1. Tipologia clauzelor. Excepții generale}

În general, tratatele privind promovarea și protejarea reciprocă a investițiilor (tratate bilaterale de investiții - "TBI") pot introduce clauze inspirate sau similare ca efect celor din GATT. Practica unor state este de a introduce în TBI clauze privind "interesele esenţiale de securitate" sau de a nu introduce nicio clauză care să justifice astfel de excepții ${ }^{16}$. În trecut, statele nu obișnuiau să introducă „excepții generale” în TBI - singura excepție fiind Canada: practica acestui stat a fost constantă de a introduce în TBI excepții ,de tipul articolului XX din GATT", în 2008 o astfel de clauză fiind în 18 din cele 24 de TBI încheiate de Canada și "modelul de TBI" utilizat de Canada include o astfel de clauză începând din $2003{ }^{17}$. În acordul de investiții semnat de România și Canada în anul 2009 este de asemenea inclusă o astfel de clauză ${ }^{18}$. De asemenea, practica Germaniei este de a include excepții care să acopere sănătatea publică ${ }^{19}$.

Dezvoltările recente în materia acordurilor de investiții constată, în paralel cu expansiunea textelor acordurilor, includerea cu precădere unor clauze care să reglementeze „excepții generale”, care să acopere inclusiv protecția sănătății umane, animale sau a plantelor (similare articolului XX b) din GATT). Astfel, conform unui studiu al Conferinței Naţiunilor Unite pentru Comerț și Dezvoltare, din 18 TBI semnate în anul 2013, 15 au inclus excepții generale de acest tip ${ }^{20}$.

\footnotetext{
${ }^{13}$ Ibid., para. 7.72 .

${ }^{14}$ Ibid., para. 7.82., 7.101.

15 Ibid., para. 7.148 .

${ }^{16}$ Practica Regatului Unit al Marii Britanii și Irlandei de Nord este de a nu introduce niciun fel de excepții în tratatele de investiții, lăsând posibilitatea ca măsurile contrare tratatelor să fie justificate exclusive prin dreptul cutumiar în material răspunderii statelor pentru fapta international ilicită - a se vedea, spre exemplu, National Grid v. Argentina, UNCITRAL Arbitration, Award of 3 November 2008, Case 1:09-cv-00248-RBW - cazul a fost iniţiat în baza TBI între Marea Britanie și Argentina, care nu conținea nicio clauză, singura justificare fiind starea de necesitate din dreptul cutumiar international - para. 245.

${ }^{17}$ Andrew Newcombe, General Exceptions in International Investment Agreements, Draft Discussion Paper Prepared for BIICL Eighth Annual WTO Conference 13th and 14th May 2008, London, available at https://www.biicl.org/files/3866_andrew newcombe.pdf (consultat 12 aprilie 2020), p. 4.

${ }_{18}$ Acordul între Guvernul României și Guvernul Canadei pentru promovarea și protejarea reciprocă a investițiilor, semnat la București, la 8 mai 2009, ratificat prin Legea nr. 356/2011, publicată în M. Of. nr. 808/26 noiembrie 2011, art. XVII, para. 3 - acest tratat urmează a fi înlocuit de Acordul economic și comercial cuprinzător UE - Canada, care se aplică provizoriu de la 21 septembrie 2017.

${ }^{19}$ William W. Burke-White, Andreas von Staden, Investment Protection in Extraordinary Times: The Interpretation and Application of Non-Precluded Measures Provisions in Bilateral Investment Treaties, Virginia Journal of International Law, vol. 48, issue 2 (2008), p. 308-410, 327, 334.

${ }^{20}$ UNCTAD, World Investment Report 2014, United Nations Publications, Sales No. E.14.II.D.1, 2014 , p. 117.
} 
Un exemplu recent este Acordul economic și comercial cuprinzător UE - Canada (cunoscut sub abrevierea „CETA”), semnat la Bruxelles, la 30 octombrie 2016, care se aplică provizoriu începând cu 21 septembrie 2017. Textul Acordului practic ,încorporează” excepțiile prevăzute de articolul XX din GATT, însă sfera de aplicare a excepțiilor generale este limitată la secțiunile B (stabilirea investițiilor) și C (tratamentul nediscriminatoriu) ${ }^{21}$. Remarcăm importanța acordată acestei clauze de Curtea de Justiţie a Uniunii Europene: în avizul 1/17 din 30 aprilie $2019^{22}$, Curtea de la Luxemburg a identificat două criterii pentru evaluarea compatibilității sistemului de soluționare a diferendelor prevăzut de CETA cu dreptul UE: sistemul de soluţionare a diferendelor să nu aibă competența de a interpreta dreptul Uniunii și să nu afecteze dreptul instituţiilor de a reglementa. Unul din argumentele pentru verificarea îndeplinirii celui de-al doilea criteriu a fost existența excepțiilor generale similare articolului XX din $\mathrm{GATT}^{23}$.

O excepție generală similară articolului XX din GATT ar reprezenta, în opinia noastră, un argument serios pentru aplicarea unor măsuri necesare pentru combaterea unei pandemii - cu respectarea criteriilor de "echilibru" și "necesitate" reținute și de practica sistemului de soluționare a diferendelor din cadrul $\mathrm{OMC}^{24}$.

\section{Excepții privind interesele esențiale de securitate}

Dacă în cazul excepțiilor generale, numărul TBI care conțin astfel de clauze este (încă) relativ redus, majoritatea TBI conțin excepții referitoare la "securitate", în general, sau, mai precis, la "interese esențiale de securitate" - după modelul articolului XXI din GATT. ${ }^{25}$ O astfel de clauză se regăsește și în practica României - spre exemplu în acordurile privind promovarea și protejarea reciprocă a investiţiilor cu Statele Unite ale Americii ("măsurile necesare menținerii ordinii publice [...] sau protejării intereselor esențiale de securitate") ${ }^{26}$ Kazahstan ("a) interese esențiale de securitate; b) menținerea ordinii publice - cu condiția să nu fie o discriminare injustă sau arbitrară sau o restricție ascunsă a investiției”) ${ }^{27}$.

Clauze privind "interesele esenţiale de securitate" - existente în tratate bilaterale de comerț și prietenie încheiate la mijlocul secolului al XX-lea - au făcut și obiectul scurtei examinări a Curții Internaționale de Justiție: în cazul Activități militare și paramilitare în Nicaragua și împotriva acesteia, Curtea a reținut că acest concept ”a făcut obiectul unei

\footnotetext{
${ }^{21}$ Articolul 28.3.2; Catherine Titi, Right to Regulate, in Makane Moise Mbengue, Stefanie Schracherer, Foreign Investment under the Comprehensive Economic and Trade Agreement, Springer, 2019, p. 159-185, 178.

${ }^{22}$ Avizul nr. 1/17 (Acordul economic și comercial cuprinzător între UE și Statele Membre, pe de o parte, și Canada, pe de altă parte), 30 aprilie 2019, ECLI:EU:C:2019:341.

${ }^{23}$ Ibid., para. 152.

${ }^{24}$ William W. Burke-White, Andreas von Staden, loc. cit., p. 361-364.

${ }^{25}$ Ibid, p. 332, 349; M. Sornarajah, International Law on Foreign Investment, Cambridge University Press, 2010, p. 222-224.

${ }^{26}$ Tratatul între Guvernul României și Guvernul Statelor Unite ale Americii privind încurajarea și protejarea reciprocă a investițiilor, semnat la București, la 28 mai 1992, ratificat prin Legea nr. 110/1992, publicată în M.Of. nr. 293/20 noiembrie 1992, art. X.

${ }^{27}$ Acordul între Guvernul României și Guvernul Republicii Kazahstan privind promovarea și protejarea reciprocă a investițiilor, semnat la Astana, la 2 martie 2010, ratificat prin Legea nr. 220/2010, publicată în M. Of. Nr. 789/25 noiembrie 2010, art. 3 (4).
} 
interpretări foarte largi în trecut" ${ }^{28}$, iar în cazul Platformele petroliere, curtea a notat că părțile nu contestau faptul că aspecte precum securitatea navelor și echipajelor, precum și caracterul neîntrerupt al comerțului în Golful Persic ar fi reprezentat interese de securitate rezonabile. $^{29}$

„Interesele esenţiale de securitate” au făcut obiectul interpretării de către tribunalele internaționale arbitrale în materia investițiilor, în special în contextul crizei financiare din Argentina din anii 2001-2002 ${ }^{30}$. În mai multe situații, ca "primă abordare", tribunalele din cadrul Centrului Internațional pentru Reglementarea Diferendelor relative la Investiții (CIRDI - ICSID) au abordat la modul restrictiv această excepție, realizând "echivalența" dintre noțiunea de interese esențiale de securitate și starea de necesitate - cauză care înlătură caracterul ilicit al unei fapte internaționale, în conformitate cu dreptul internațional cutumiar $^{31}$. În cazul $C M S c$. Argentina, tribunalul a stabilit echivalența dintre „interesele naționale de securitate și articolul 25 din Articolele Comisiei de Drept Internațional privind răspunderea statelor pentru fapta internațională ilicită și a arătat că, în Argentina, criza economică nu cauzase un „colaps total”32. În cazul Sempra c. Argentina, tribunalul a recunoscut, de asemenea, că prevederile referitoare la securitate sunt inseparabile în raport cu dreptul internațional cutumiar ${ }^{33}$. O abordare similară a fost adoptată în cazul $C$. Enron c Argentina: după ce tribunalul a examinat starea de necesitate în conformitate cu dreptul cutumiar și a ajuns la concluzia că nu sunt îndeplinite condițiile pentru invocarea acesteia, a apreciat că "nu este nevoie să fie examinat articolul XI [interesele esenţiale de securitate], intrucât acest articol nu reglementează condiții diferite față de cele ale dreptului cutumiar în această privință ${ }^{\prime 3}$.

Abordarea a fost diferită în cazul Continental Casualty c. Argentina, în care tribunalul a admis că, deși există o legătură între clauza privind interesele esenţiale de securitate (articolul XI din TBI între SUA și Argentina) și articolul 25 din Articolele Comisiei de Drept Internațional privind răspunderea statelor pentru fapta internaţională ilicită, "invocarea prevederii specifice care limitează obligațiile generale privind protecția investițiilor (de natură „primară”) agreată bilateral de Părți, nu este în mod necesar supusă acelorași condiții care starea de necesitate în conformitate cu dreptul internațional cutumiar" 35 . Această ultimă abordare a fost reținută și de Comitetele Ad-hoc care au analizat cererile de

\footnotetext{
${ }^{28}$ Militarv and Paramilitary Activities in und against Nicaragua (Nicaragua v. United States of America), Merits, Judgment, I.C.J. Reports 1986, p. 14, 117, para. 224 - Curtea a interpretat articolul XXI din Tratatul de comerț, prietenie și navigație dintre SUA și Nicaragua din 1956 și a remarcat diferența dintre acest articol și articolul XXI GATT, în sensul că în tratatul bilateral lipsea determinarea de către una dintre părți - [măsuri] "pe care le consideră necesare" - p. 116, para. 222.

${ }^{29}$ Oil Platforms (lsamic Republic of Iran v. United States of America), Judgment, I. C. J. Reports 2003, p. 161, 196, para. 73 - Curtea s-a referit la articolul XX din Tratatul de comerț, prietenie și navigație între SUA și Iran din 1955, însă nu a examinat pe fond acest argument, interesele esențiale de securitate fiind incorporate în criteriile legitimei apărări; William W. Burke-White, Andreas von Staden, loc. cit., p. 350.

${ }^{30}$ William J. Moon, Essential Security Interests in International Investment Agreements, Journal of International Economic Law, vol. 15, Issue 2, 2012, p. 481-502.

${ }^{31}$ Ibid., p. 485-490.

32 Ibid, p. 485; CMS c. Argentina, ICSID Arb/01/08, 12 May 2005, para. 88.

${ }^{33}$ Sempra c. Argentina, ICSID Arb/01/3, 28 September 2007, para. 331-332.

${ }^{34}$ C. Enron v. Argentina, ICSID Arb/01/3, 22 May 2007, para. 339.

${ }^{35}$ Continental Casualty v. Argentina, ICSID Arb/03/9, 5 September 2008, para. 167-168.
} 
anulare - acestea a respins teza inițială a tribunalelor din cazurile $C M S$ c. Argentina, $C$. Enron c. Argentina și Sempra c. Argentina și au constatat că ignorarea analizării condițiilor din articolul XI din TBI (interesele esențiale de securitate), independent față de dreptul cutumiar, reprezintă o eroare manifestă de drept ${ }^{36}$. In Sempra c. Argentina, Comitetul ad-hoc a argumentat detaliat distincția dintre cele două norme și a arătat că articolul XI din TBI nu include aceleași „cerințe stricte” precum starea de necesitate ("pericol grav și iminent” sau "unica modalitate") 37 .

În orice caz, oricât de restrictivă ar fi interpretarea clauzei din TBI referitoare la „interese esențiale de securitate”, tribunalele arbitrale au arătat că dificultăţile economice se pot încadra în această noțiune. În cazul $L G \& E$ c. Argentina, deși, în final, a respins argumentul, tribunalul a reținut, cu titlu general:

"Tribunalul respinge ideea că Articolul XI este aplicabil numai în circumstanțe care reprezintă acțiune militară sau război. In mod cert, condițiile din Argentina din decembrie 2001 au cerut acțiune imediată și decisivă pentru a restaura ordinea civică și a opri declinul economic. A concluziona că o criză economică atât de severă nu ar putea constitui un interes esențial de securitate înseamnă a ignora haosul pe care criza economică poate să îl cauzeze populației și abilitatea guvernului de a răspunde acestuia. Când fundamentele economiei unui stat sunt sub asediu, severitatea problemei poate fi echivalentă invaziei militare" 38 .

\section{Scurtă concluzie}

Oricare dintre cele două clauze examinate - excepțiile generale și interesele esențiale de securitate - pot fi invocate cu succes în ceea ce privește măsurile necesare pentru combaterea pandemiei COVID-19. În ambele cazuri, criteriul „necesității” și verificarea "echilibrului” sau ,proporționalităţii” între valorile protejate prin măsura concretă adoptată şi ingerințele rezultate din acea măsură în ceea ce privește comerțul internațional sau tratamentul acordat investitorilor trebuie analizate de la caz la caz (de exemplu - în opinia noastră - dacă interdicția exportării medicamentelor sau produselor sanitare pentru a face față necesităţilor sistemului sanitar în timpul pandemiei ar putea fi o măsură necesar și proporțională, o interzicere totală a exporturilor dintr-un anumit stat nu ar răspunde acestor criterii).

În ceea ce privește „excepțiile generale”, constatăm că la prima vedere acestea stabilesc un criteriu mai ușor de atins, întrucât sănătatea publică ("protecția vieții oamenilor") este expres prevăzută. Totuși, așa cum rezultă din jurisprudența arbitrală examinată, răspunsul față de criza cauzată de pandemie se poate încadra și în noțiunea de „,interese esenţiale de securitate”. Dacă o criză economică precum cea din Argentina din

\footnotetext{
${ }^{36}$ CMS Gas Transmission Co. v. Argentine Republic, ICSID Case No. Arb 01/08, Decision of the Ad-hoc Committee on the Application for Annulment of the Argentine Republic (25 September 2007), para. 146, Sempra c. Argentina, ICSID Arb/01/3, Decision of the Ad-hoc Committee on the Application for Annulment of the Argentine Republic (29 June 2010), para. 109-118, C. Enron v. Argentina, ICSID Arb/01/3, Decision of the Ad-hoc Committee on the Application for Annulment of the Argentine Republic (30 July 2010), para. 405; William J. Moon, loc. cit., p. 489.

${ }^{37}$ Sempra c. Argentina, ICSID Arb/01/3, Decision of the Ad-hoc Committee on the Application for Annulment of the Argentine Republic (29 June 2010), para. 117.

${ }^{38} L G \& E$ c. Argentina, ICSID Arb/02/1, Decision of 3 October 2006, para. 238.
} 
2001-2002 a fost apreciată, la modul general, ca o situație de acest gen, nimic nu ar exclude încadrarea pandemiei COVID-19 într-o prevedere similară. Cu titlu exemplificativ, Consiliul de Securitate al ONU a considerat, în $2014^{39}$, că o epidemie (de amploare mai scăzută decât COVID-19) poate reprezenta o amenințare la adresa păcii și securităţii internaţionale. Prin urmare, încadrarea în noțiunea "interese esențiale de securitate" reprezintă un argument plauzibil și rezonabil.

Materialul a fost publicat în revista online a Facultăţii de Drept, $\underline{\text { AUBD - Forum Juridic nr. }}$ $\underline{1 / 2020 .}$

\section{Bibliografie}

\section{Cărți și articole}

Bartels, L., The Chapeau of the General Exceptions in the WTO GATT and GATS Agreements: A Reconstruction, American Journal of International Law, vol. 109 (2015), p. 95-125

Burke-White, W.W., Von Staden, A., Investment Protection in Extraordinary Times: The Interpretation and Application of Non-Precluded Measures Provisions in Bilateral Investment Treaties, Virginia Journal of International Law, vol. 48, issue 2 (2008), p. 308-410

Hailes, O., Epidemic Sovereignty? Contesting investment treaty claims arising from coronavirus measures, EJIL: Talk!, Blog of the European Journal of International Law, 27 March 2020,

https://www.ejiltalk.org/epidemic-sovereignty-contesting-investment-treaty-claims-arising-from-coronavirusmeasures/ (accesat 12 aprilie 2020)

Moon, W. J., Essential Security Interests in International Investment Agreements, Journal of International Economic Law, vol. 15, Issue 2, 2012, p. 481-502

Newcombe, A., Paradell, L., Law and Practice of Investment Treaties. Standards of Treatment, Wolters Kluwer, 2009

Newcombe, A., General Exceptions in International Investment Agreements, Draft Discussion Paper Prepared for BIICL Eighth Annual WTO Conference 13th and 14th May 2008, London, available at https://www.biicl.org/files/3866_andrew_newcombe.pdf (consultat 12 aprilie 2020)

Paddeu, F., Jephcott, F., COVID-19 and Defences in the Law of State Responsibility: Part I/Part II, EJIL: Talk!, Blog of the European Journal of International Law, 17 March 2020, https://www.ejiltalk.org/covid-19-anddefences-in-the-law-of-state-responsibility-part-i/, https://www.ejiltalk.org/covid-19-and-defences-in-the-lawof-state-responsibility-part-ii/ (accesat 12 aprilie 2020)

Schloemann, H. L., Ohlhoff, S., “Constitutionalization” and Dispute Settlement in the WTO: National Security as an Issue of Competence, American Journal of International Law, vol. 93 (1999), p. 424-444

Sornarajah, M., International Law on Foreign Investment, Cambridge University Press, 2010

Van den Bossche, P. The Law and Policy of the World Trade Organization, Cambridge University Press, 2005

Titi, C., Right to Regulate, in Makane Moise Mbengue, Stefanie Schracherer, Foreign Investment under the Comprehensive Economic and Trade Agreement, Springer, 2019, p. 159-185

${ }^{39}$ Rezoluția Consiliului de Securitate nr. 2177 (2014). 


\section{Cazuri}

CIJ

Militarv and Paramilitary Activities in und against Nicaragua (Nicaragua v. United States of America), Merits, Judgment, I.C.J. Reports 1986, p. 14

Oil Platforms (lsamic Republic of Iran v. United States of America), Judgment, I. C. J. Reports 2003, p. 161

CJUE

Avizul nr. 1/17 (Acordul economic și comercial cuprinzător între UE și Statele Membre, pe de o parte, și Canada, pe de altă parte), 30 aprilie 2019, ECLI:EU:C:2019:341

OMC

Thailand - Restrictions on Importation of and Internal Taxes on Cigarettes, Report of the Panel adopted on 7 November 1990 (DS10/R - 37S/200)

Appellate Body Report, United States - Standards for Reformulated and Conventional Gasoline, WT/DS2/AB/R, adopted 20 May 1996

Appellate Body Report, United States - Import Prohibition of Certain Shrimp and Shrimp Products, WT/DS58/AB/R, adopted 6 November 1998

Appelate Body Report, Korea - Various measures on Beef, WT/DS161/AB/R, WT/DS169/AB/R, 11 December 2000

Appellate Body Report, European Communities — Measures Affecting Asbestos and Asbestos-Containing Products, WT/DS135/AB/R, adopted 5 April 2001

Panel Report, Russia - Measures concerning Traffic in Transit, WT/DS512/R, 5 April 2019

\section{CIRDI/ICSID}

CMS c. Argentina, ICSID Arb/01/08, 12 May 2005

$L G \& E$ c. Argentina, ICSID Arb/02/1, Decision of 3 October 2006

Sempra c. Argentina, ICSID Arb/01/3, 28 September 2007

C. Enron v. Argentina, ICSID Arb/01/3, 22 May 2007

Continental Casualty v. Argentina, ICSID Arb/03/9, 5 September 2008

CMS Gas Transmission Co. v. Argentine Republic, ICSID Case No. Arb 01/08, Decision of the Ad-hoc Committee on the Application for Annulment of the Argentine Republic (25 September 2007)

Sempra c. Argentina, ICSID Arb/01/3, Decision of the Ad-hoc Committee on the Application for Annulment of the Argentine Republic (29 June 2010)

C. Enron v. Argentina, ICSID Arb/01/3, Decision of the Ad-hoc Committee on the Application for Annulment of the Argentine Republic (30 July 2010)

\section{UNCITRAL}

National Grid v. Argentina, UNCITRAL Arbitration, Award of 3 November 2008, Case 1:09-cv-00248-RBW 


\section{Alte documente}

International Law Commission, Articles on the Responsibility of States for International Wrongful Acts (with commentaries), 2001, Yearbook of the International Law Commission, 2001, vol. II

UNCTAD, World Investment Report 2014, United Nations Publications, Sales No. E.14.II.D.1, 2014 